\title{
Empowerment, climate change adaptation, and agricultural production: evidence from Niger
}

\author{
Fleur Wouterse ${ }^{1}$
}

Received: 23 March 2017 / Accepted: 13 October 2017 /Published online: 30 October 2017

(C) The Author(s) 2017. This article is an open access publication

\begin{abstract}
We use new household level data from Niger and regression analysis to study the role of drought perception and human capital — including empowerment — in climate change adaptation through the digging of zaï pits and effects of these pits on agricultural productivity. We find that selection of households into adoption of zaï pits is influenced by the perception that the frequency of droughts has increased. More educated, experienced, and empowered households are also more likely to have put in place zaï pits. Accounting for endogeneity of adoption, zaï pits are found to significantly increase cereal yields. Our counterfactual analysis reveals that even though all households would benefit from adoption of zai pits, the effect would be significantly larger for households that did not adopt if they had adopted. For the latter group, empowerment in particular is associated with significantly higher yields.
\end{abstract}

\section{Introduction}

Climate change poses potentially large risks for farmers in the developing world affecting yields, growing seasons, water availability, and increasing weather uncertainties (Nelson et al. 2009). Smallholders in drought-prone Niger are well-acquainted with how a changing climate affects their crop production and have long adjusted their management practices to address negative impacts of climate. One adaptative strategy that is pursued in the face of climatic stressors is the digging of zaï pits, which are small holes (diameter 20-40 cm and depth 10 $20 \mathrm{~cm}$ ) filled with compost and planted with seeds. Zaï pits contribute to both agronomic and economic productivity and resilience and adaptive capacity of households and are considered key for climate smart agriculture planning for farm-level interventions in the country. Given that climate change will likely exacerbate climate variability and extreme events, an understanding of drivers and obstacles to zaï pit adoption and returns to agricultural production is critical to facilitate and enhance adaptation to climate change and for developing well-targeted policies.

Fleur Wouterse

f.wouterse@cgiar.org

1 International Food Policy Research Institute c/o International Institute of Social Studies, The Hague, The Netherlands 
Considerable research exists on adaptation strategies (see Burnham and Ma 2016 for an overview) but empirical evidence is lacking as to the role that climate change perception plays in adaptation and on the importance of a broader concept of human capital in the decision to adapt. Although it has been suggested that farmer perceptions regarding long-term climatic changes affect adaptation (Maddison 2007), this has not yet been formally established. Formal education has been identified as a driver of adaptation but because climate change adaptation is endogenous to society and influenced by values, there is a need to consider the agency —or the ability to make strategic life choices - of adaptation decision making (Adger et al. 2009). Empowerment, which is the expansion of agency, is likely to play an important role in climate change adaptation decisions but to our knowledge, the contribution of empowerment to adaptation has not yet been empirically established. Establishment of a formal link between perception and adaptation and empirical evidence as to the role that empowerment plays in adaptation and productivity constitute two important gaps in the literature.

In this paper, we aim to contribute to the literature by investigating the use of zaï pits as an adaptative strategy in Niger. Using new household-level data from the Tahoua region, we model adaptation decision-making and returns to adaptation at the farm household level. In particular, we empirically establish a link between climate change perception and adaptation. We also assess the importance of empowerment in adaptation decision making and in productivity outcomes. Our results reveal that households that perceived increased drought were more likely to have employed zaï pits. Inadequacy in empowerment emerges as an important constraint to zaï pit adoption. Results from our production function estimation show that adaptation to climate change through the digging of zaï pits is associated with higher yields. The impact of adaptation on food productivity would be particularly large for farm households that did not adapt in the counterfactual case that they adapted. Empowerment is found to contribute positively to yields in the more vulnerable non-adopting households. In terms of policy implications, this study demonstrates that climate change adaptation can be autonomous and that interventions aimed at empowering households, particularly those that are most vulnerable, would be effective in promoting adaptation and productivity.

\section{Climate vulnerability and adaptation decision-making}

Located at the heart of West Africa, Niger is a landlocked country with three quarters of its territory covered by the Sahara Desert. Niger's climate is mostly arid with a rainfall gradient ranging from 100 to $700 \mathrm{~mm}$ of annual rainfall and it is one of the least-developed countries in the world, ranking 186th per the Human Development Index (UNDP 2013). The clear majority of its population (82\%) live in rural areas and the country is strongly dependent on agriculture, which contributed about $36.4 \%$ to the GDP in 2015 (World Bank 2016). The agricultural sector is dominated by smallholders and generally rainfed. Yields rely on a single rainy season that runs from May to September. Although productivity has shown a positive trend, agriculture has been strongly affected in recent decades by several crises due - partly or entirely - to extreme weather events such as the droughts of 1973, 1984-1985, and more recently 2005 and 2009 (World Bank 2013). There is thus considerable discussion on how to make agriculture, the main sector in which the poor are involved and especially smallholder agriculture, more resilient to extreme events as well as adapted to shifts in potential climate conditions (Howden et al. 2007). Climate-smart agriculture (CSA) - farming systems that increase agricultural productivity, improve the adaptive capacity of farmers, and mitigate climate change where 
possible - has been put forward as a solution to the food and climate challenges Africa faces (Lamanna et al. 2015).

\subsection{Adaptation strategies for soil and water conservation in rural Niger}

Adaptation to climate change can be defined as an adjustment in ecological, social, or economic systems in response to observed or expected changes in climatic stimuli and their effects and impacts to alleviate adverse impacts of change or take advantage of new opportunities (Adger et al. 2005). Adaptation is an ongoing and dynamic process whereby societies continually respond to changing socioeconomic, technological, and resource regimes. Adaptation can occur at various levels and can be autonomous or planned where the former are initiatives by private actors rather than by governments usually triggered by welfare changes induced by actual or anticipated climate change (IPCC 2014).

During a period of severe drought in the Sahel in the early 1980s, farmers in Burkina Faso began "innovating out of despair" by experimenting with planting pits, a technique practiced for many years by farmers elsewhere in the Sahel (Reij et al. 2009). The innovation was, first, to increase the diameter $(20-40 \mathrm{~cm})$ and depth of the pits $(10-$ $20 \mathrm{~cm}$ ) and second, to concentrate nutrients and moisture in the pits. After digging these so-called zaï pits on severely degraded farmland that was otherwise impermeable to water, organic matter was added and - after the first rainfall - the matter would be covered with a thin layer of soil and millet and/or sorghum seeds placed in the middle of the pit. The zaï pits dramatically improved soil fertility by capturing soil and organic matter from the wind attracted termites which enhanced soil nutrients, increase water retention, and increase the cost-effectiveness of manure and fertilizer application. The practice of zaï pits spread to neighboring Niger after a study visit of farmers from the Tahoua region of Niger to Burkina Faso in 1989. The technique has spread at a surprising rate in rural Niger, adding an additional 2-3 ha per year to some holdings (IFAD 2010). Zaï pits are autonomous rather than planned adaptations as the government of Niger and NGOs promoted the more expensive contour stone bunds and half-moons as preferred forms of in-field soil and water conservation endorsed by researchers. Stone bunds, established along the contours of the land and where stones or rocks are available, slow water runoff to improve water catchment capacity. Half-moon micro catchments are small, semicircular earth bunds. These are quite common on the desert margins of the Sahel. The half-moons catch water flowing down a slope. Half-moons are particularly helpful to rehabilitate degraded land.

Zaï pits have been associated with important improvements in yields because they simultaneously address issues of land degradation, soil fertility, and soil moisture. In Burkina Faso, in fields that had been yielding virtually no grain, farmers recorded yields of $300 \mathrm{~kg} / \mathrm{ha}$ (in years with low rainfall) to $1200 \mathrm{~kg} / \mathrm{ha}$ (in years of good rainfall) upon digging zaï pits (Kaboré and Reij 2004). By improving soil water holding capacity, zaï pits also help households buffer against drought-induced food shocks thereby improving resilience. Because zaï pits contribute to two of the pillars of climate-smart agriculture - agronomic and economic productivity and resilience and adaptive capacity of households - they are thought to be key for climate-smart agriculture planning for farm-level interventions in the country (Lamanna et al. 2015). It is thus important to understand the driving forces behind climate change adaptation in the form of the adoption of zaï pits. 


\subsection{Adaptation decision-making}

The discourse around limits to adaptation is traditionally constructed around three immutable thresholds - ecological and physical, economic, and technological. For example, given that adaptation requires investments, studies tend to first and foremost consider its economic feasibility using cost-benefit analysis where benefits are on-site land productivity gains. Recent research has posited that socio-cognitive factors may be as important as or more important than economic ones in motivating individuals to take adaptive actions (Grothmann and Patt 2005). Relevant characteristics are thought to include beliefs, preferences, perceptions of self-efficacy, and controllability. These together with among others perceptions of risk, knowledge, and experience determine what is perceived to be a limit to adaptation and what is not (Adger et al. 2009).

Here, we focus on perception of risk and on human capital defined as the aggregation of the innate abilities and the knowledge and skills that individuals acquire and develop throughout their lifetime (Laroche et al. 1999) to explain climate change adaption decision-making in the form of the implementation of zaï pits. Perception of hazard risk has long been recognized as a critical determinant of human response to environmental shocks. In Grothmann and Patt's (2005) Model of Private Proactive Adaptation to Climate Change (MPPACC), for example, perception is a key variable illustrated as influencing or being influenced by all the model's determinants of adaptive behavior. Although the definition of human capital as given above is sufficiently broad, in practice, knowledge has often become synonymous with formal education and skills with experience. Notwithstanding the relevance of formal education and experience in adaptation decision-making, Adger et al. (2009) have postulated that the agency of adaptation decision-making may also be important. Agency refers to the ability to define one's goals and act upon them. Agency also encompasses the meaning, motivation, and purpose that individuals bring to their activity, their sense of agency, or the "power within". The Women's Empowerment in Agriculture Index (WEAI) - originally developed for USAID's Feed the Future program - is based on the agency dimension of empowerment, which is far less studied than resources such as income or achievements (Alkire et al. 2013).

The WEAI is a survey-based index, which builds up a multidimensional empowerment profile for the primary male and female decision-maker in a household that reflects their overlapping achievements in five domains and aggregates these. The WEAI is a weighted average of two subindexes: (1) the five domains of empowerment (5DE) and (2) gender parity (the Gender Parity Index (GPI)). The former captures the roles and extent of engagement in the agricultural sector in five domains: (1) decisions about agricultural production, (2) access to and decision-making power about productive resources, (3) control of use of income, (4) leadership in the community, and (5) time allocation. Table 1 describes the ten indicators that are used in the five domains.

Each indicator takes the value of 1 when the individual is considered as adequate and 0 otherwise. The GPI is a relative inequality measure that reflects the inequality in 5DE profiles between the primary adult male and female in each household. Wouterse (2017) has used the 5DE to show for rural Niger that more empowered households are more productive while Seymour et al. (2016) use the 5DE scores of women measured to explain adoption of improved varieties by rural households in Ethiopia, Kenya, and Tanzania. They find that the empowerment of women is positively correlated with increased participation in decisions about the adoption of improved varieties. With limits to adaptation contingent on values (Adger et al. 2009), an analysis of household level decision-making, which incorporates perception and empowerment, is indispensable to a better understanding of adaptation and informing policy. 
Table 1 The domains, indicators, and weights in the WEAI

\begin{tabular}{|c|c|c|c|}
\hline Domain & Indicator & Definition of indicator & Weight \\
\hline \multirow[t]{2}{*}{ Production } & Input in productive decisions & $\begin{array}{l}\text { Sole or joint decision-making over food, } \\
\text { cash crop farming, livestock, and fisheries }\end{array}$ & $1 / 10$ \\
\hline & Autonomy in production & Autonomy in agricultural production & $1 / 10$ \\
\hline \multirow[t]{3}{*}{ Resources } & Ownership of assets & Sole or joint ownership of major household assets & $1 / 15$ \\
\hline & $\begin{array}{l}\text { Purchase, sale or transfer } \\
\text { of assets }\end{array}$ & $\begin{array}{l}\text { Whether respondent participates in decision } \\
\text { to buy, sell, or transfer his/her owned assets }\end{array}$ & $1 / 15$ \\
\hline & $\begin{array}{l}\text { Access to and decisions on } \\
\text { credit }\end{array}$ & $\begin{array}{l}\text { Access to and participation in decision-making } \\
\text { concerning credit }\end{array}$ & $1 / 15$ \\
\hline Income & Control over use of income & Sole or joint control over income and expenditures & $1 / 5$ \\
\hline \multirow[t]{2}{*}{ Leadership } & Group member & Whether respondent is an active member in a group & $1 / 10$ \\
\hline & Speaking in public & $\begin{array}{l}\text { Whether the respondent is comfortable speaking in } \\
\text { public }\end{array}$ & $1 / 10$ \\
\hline \multirow[t]{2}{*}{ Time } & Workload & Allocation of time to productive and domestic tasks & $1 / 10$ \\
\hline & Leisure & Satisfaction with the time available for leisure activities & $1 / 10$ \\
\hline
\end{tabular}

Source: Alkire et al. (2013)

\section{Data}

Data to estimate our model of adaptation decision-making were collected by the author during April-May 2015 for 500 randomly sampled households (and 769 adult individuals in these households) in 35 villages situated in three communes (Doguéraoua, Malbaza, and Tsernaoua) in the Maggia valley of the Birni N'Konni Department in the Tahoua region. ${ }^{1}$ Birni N'Konni is situated in the southern part of Niger and belongs to the Sahelo-Sudanese environment, which allows for rainfed agriculture. Household-level data were collected using a standard agricultural household survey while individual-level empowerment data were collected using the standard WEAI survey (Alkire et al. 2013). The WEAI survey tool collects data from the primary male and female decision-maker in a household on the five domains (production, resources, income, leadership, and time) that are envisaged to make up empowerment. To calculate householdlevel empowerment, we take the average of the sum of the weighted adequacy scores for the primary male and female decision-maker. Weighted scores of each indicator for men and women in our sample and their contribution to empowerment are given in Fig. 1.

Figure 1 shows that women are much more disempowered compared to men. We can also see that leadership — composed of speaking in public and group membership — strongly contributes to disempowerment for both men and women in our sample.

Farm and household descriptives by zaï adoption status are given in Table 2. Farming systems are extensive agropastoral millet and sorghum based. In our sample, about a fifth of households had dug zaï pits on their cereal plots. Less common SWC measures are stone bunds and halfmoons. The table shows that yield or the quantity of cereals harvested in kilograms per hectare during the 2014 agricultural season is significantly higher for households that had put in place zaï pits. Table 2 also shows that households that had employed zaï pits are significantly better endowed in terms of cultivated land and dispose of more valuable farming equipment. As to variable inputs, households that employ zaï pits use more days of household labor in production but there is no significant difference in terms of the quantity of fertilizer applied between households that employ zaï pits and those that do not. In general, synthetic fertilizer use is low

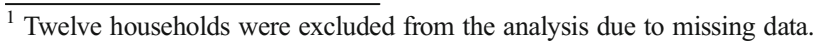




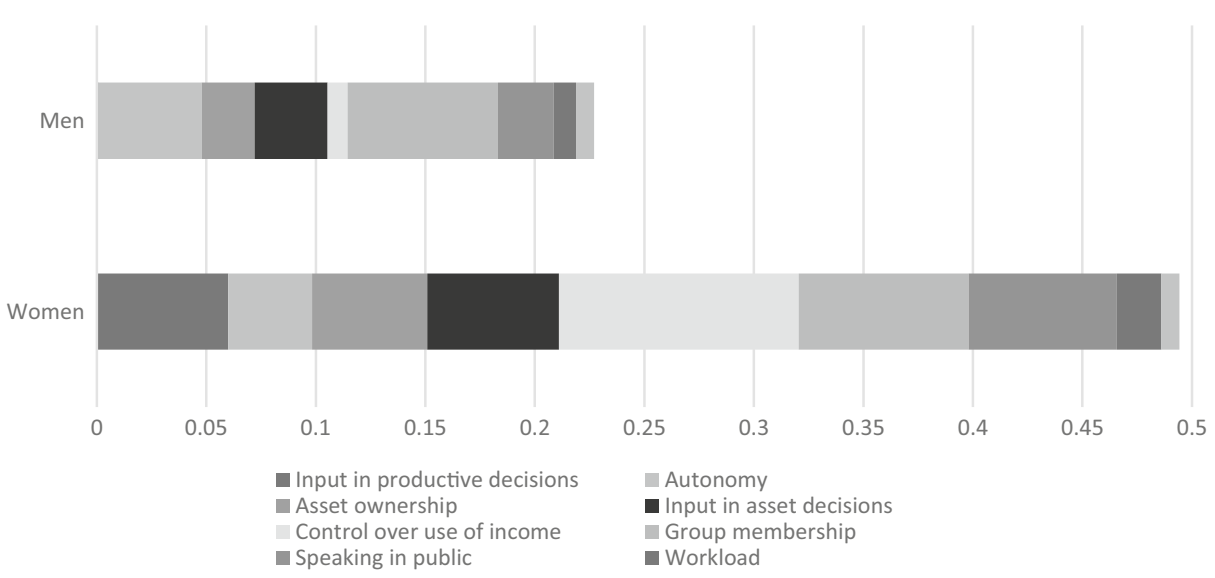

Figure 1 Contributors to inadequacy in empowerment

in the study area with less than half of households applying fertilizer and application rates are well below recommended dosages. Table 2 also shows that households that employ zaï pits are significantly more likely to have perceived an increased frequency of droughts during the 5 years preceding the survey. In terms of human capital, households who had adapted to climate change by digging zaï pits were more likely to be headed by a male, have heads who are literate, and contain more experienced adults, where experience is measured as the average of adults minus years of formal education received minus five. Households that adopted are also more likely to contain an adult member who attended Koranic school as a child but empowerment levels of households that had and had not employed zaï pits do not significantly differ.

Table 2 Farm and household descriptives

\begin{tabular}{lllr}
\hline & Adopter & Non-adopter & $t$ test \\
\hline Household level & & & \\
Cereal yield (kg/ha) & $441.28(313.52)$ & $352.71(270.81)$ & -2.80 \\
Cultivated acreage (ha) & $6.16(6.85)$ & $4.01(3.43)$ & -1.77 \\
Household labor (days/ha) & $36.25(34.14)$ & $30.23(30.23)$ & -1.72 \\
Fertilizer (kg/ha) & $3.64(7.92)$ & $3.77(9.29)$ & 0.13 \\
Seed (kg/ha) & $11.71(14.72)$ & $10.14(10.26)$ & -1.23 \\
Manure (kg/ha) & $442.69(567.15)$ & $410.15(684.32)$ & -0.43 \\
Number of cattle & $0.76(1.22)$ & $0.70(1.43)$ & -0.76 \\
Value of equipment (FCFA) & $44,488(68,726)$ & $26,588(38,859)$ & -3.41 \\
Sex of the household head (1 = male) & $0.87(0.34)$ & $0.73(0.44)$ & -2.78 \\
Literacy of household head $(1=$ yes) & $0.44(0.50)$ & $0.30(0.46)$ & -2.53 \\
Schooling of most educated adult (years) & $2.46(2.97)$ & $1.93(3.17)$ & -1.49 \\
Koranic schooling of adult & $0.59(0.49)$ & $0.27(0.45)$ & -6.22 \\
Experience of adults (years) & $28.11(12.00)$ & $26.03(10.74)$ & -1.67 \\
Empowerment & $0.66(0.17)$ & $0.65(0.17)$ & -0.56 \\
Perceives increased drought & $0.81(0.40)$ & $0.67(0.47)$ & -2.56 \\
Village level & & & -3.04 \\
High participation in migration & $0.70(0.46)$ & $0.53(0.50)$ & -2.15 \\
Distance to minibus stop & $7.61(9.61)$ & $5.09(8.21)$ & 387 \\
Number of observations & 101 & & \\
\hline
\end{tabular}

Standard deviation in parentheses; FCFA 225 = US\$1 (purchasing power parity for 2015) (World Bank 2016) 


\section{Methods}

The zaï adoption decision as a function of drought perception and human capital and its implications in terms of an outcome of interest can be modeled in the setting of a two-stage framework (see also Di Falco et al. 2011 and Abdulai and Huffman 2014). In the first stage, we use a selection model for zaï adoption where a representative risk-averse farm household chooses to implement the pits if it generates net benefits. We can therefore represent the net benefits derived from zaï adoption by a latent variable $D_{j}^{*}$, which is not observed but can be expressed as a function of the observed characteristics and attributes, denoted as $Z$, in a latent variable model as follows:

$$
D_{j}^{*}=\gamma \boldsymbol{Z}_{j}+\varepsilon_{j} \quad \text { with } \quad D_{j}=\left\{\begin{array}{l}
1, \text { if } D_{j}^{*}>0 \\
0, \text { otherwise }
\end{array}\right.
$$

In Eq. (1), $D_{j}$ is a binary variable that equals 1 for households that implement zaï pits and zero otherwise, $\gamma$ denotes a vector of parameters to be estimated. Household $j$ will choose to adopt $\left(D_{j=1}\right)$ by employing zaï pits only if the perceived net benefits are positive $D_{j}^{*}>0$. The error term $\varepsilon_{j}$ with mean zero and variance $\sigma_{\varepsilon}^{2}$ captures measurement errors and factors unobserved to the researcher but known to the farmer. Variables in $\boldsymbol{Z}$ include factors that influence the decision to adopt such as farm level and household characteristics including perception of increased drought. Although the perceived net benefits of implementation are unknown to the researcher, the characteristics of the farm household and the attributes of the technology are observed during the survey period.

In the second stage, we model the effect of adoption on productivity via a representation of the production technology. Following Di Falco et al. (2011), we use a quadratic specification of a single output production function. As cereals-millet and sorghum - constitute the bulk of agricultural production and are cultivated by all households in our sample and as zaï pits are employed on plots under cereals, we use the total yield of cereals as our outcome variable. The simplest approach to examine the impact of adoption of zaï pits on farm households would be to include a binary variable which takes the value of 1 if the household employed zaï pits and then use ordinary least squares to estimate the production function. However, because the decision to employ zaï pits may be based on individual self-selection, this approach would yield biased results. This is so because there may be unobserved heterogeneity which drives the decision to adopt and affects output. Farmers that adopt may have systemically different characteristics from farmers that did not and may have decided to adopt based on expected benefits. Given that we dispose of cross-section data only and thus have no information on the counterfactual situation and the fact that we have an actual interest in examining the determinants of household-level climate change adaption, we follow Di Falco et al. (2011) and Abdulai and Huffman (2014) and employ the endogenous switching regression model developed by Lee (1982).

The endogenous switching regression approach as a generalization of Heckman's selection correction approach, accounts for selection on unobservables by treating selectivity as an omitted variable problem (Heckman 1979). In the switching regression approach, households are classified per their status as adopters and non-adopters 
to capture the differential responses of the two groups. Regimes are defined as follows:

$$
\text { Regime } 0(\text { Not adopt }): Y_{N j}=\boldsymbol{X}_{N j} \boldsymbol{\beta}_{\boldsymbol{N}}+u_{N j} \quad \text { if } D_{j}=0
$$

$$
\text { Regime } 1 \text { (Adopt) : } Y_{A j}=\boldsymbol{X}_{A j} \boldsymbol{\beta}_{\boldsymbol{A}}+u_{A j} \quad \text { if } D_{j}=1
$$

In Eqs. (2a) and (2b), $Y_{j}$ is quantity produced per hectare in regimes 0 and 1 and $\boldsymbol{X}_{N j}$ and $\boldsymbol{X}_{A j}$ are vectors of weakly exogenous inputs (seed, labor, and fertilizer) and farm and household characteristics; $\boldsymbol{\beta}_{\boldsymbol{N}}$ and $\boldsymbol{\beta}_{\boldsymbol{A}}$ are vectors of parameters and $u_{N j}$ and $u_{A j}$ are independently and identically distributed errors. The error terms in Eqs. (1) and $(2 \mathrm{a}(\mathrm{a}-\mathrm{b}))$ are assumed to have a trivariate normal distribution with mean vector 0 and the following covariance matrix:

$$
\operatorname{cov}\left(\varepsilon, u_{A}, u_{N}\right)=\Sigma=\left[\begin{array}{ccc}
\sigma_{\varepsilon}^{2} & \sigma_{\varepsilon A} & \sigma_{\varepsilon N} \\
\sigma_{A \varepsilon} & \sigma_{A}^{2} & \cdot \\
\sigma_{N \varepsilon} & \cdot & \sigma_{N}^{2}
\end{array}\right]
$$

where $\operatorname{var}\left(u_{A}\right)=\sigma_{A}^{2}, \operatorname{var}\left(u_{N}\right)=\sigma_{N}^{2}, \operatorname{var}(\varepsilon)=\sigma_{\varepsilon}^{2}, \operatorname{cov}\left(u_{A}, \varepsilon\right)=\sigma_{A \varepsilon}$, and $\operatorname{cov}\left(u_{N}, \varepsilon\right)=\sigma_{N \varepsilon}$. The covariance between $u_{A}$ and $u_{N}$ is not defined because $Y_{N j}$ and $Y_{A j}$ are not observed simultaneously. An important implication of the error structure is that because the error term of the selection equation is correlated with the error terms of the productivity functions, the expected values of $u_{N j}$ and $u_{A j}$ conditional on sample selection are non-zero:

$$
\begin{aligned}
& E\left(u_{A j} \mid D=1\right)=\sigma_{A \varepsilon} \rho_{A} \frac{\varphi\left(\boldsymbol{Z}_{\boldsymbol{j}} \gamma\right)}{\Phi\left(\boldsymbol{Z}_{\boldsymbol{j}} \gamma\right)} \\
& \text { and } E\left(u_{N j} \mid D=0\right)=-\sigma_{N \varepsilon} \rho_{N} \frac{\varphi\left(\boldsymbol{Z}_{\boldsymbol{j}} \gamma\right)}{1-\Phi\left(\boldsymbol{Z}_{\boldsymbol{j}} \gamma\right)}
\end{aligned}
$$

where $\varphi$ and $\Phi$ are the probability density and cumulative distribution function of the standard normal distribution respectively and $\rho_{A}$ is the correlation coefficient between $u_{A j}$ and $\varepsilon_{j}$ and $\rho_{N}$ is the correlation coefficient between $u_{N j}$ and $\varepsilon_{j}$. The ratio of $\varphi$ and $\Phi$ evaluated at $\mathbf{Z}_{j} \gamma$ is referred to as the inverse Mills ratio and accounts for selfselection into one of the two regimes. If the estimated covariances $\hat{\sigma}_{A \varepsilon}$ and $\hat{\sigma}_{N \varepsilon}$ are statistically significant, then the decision to employ zaï pits and yields are correlated; we would thus reject the absence of sample selectivity bias and use an endogenous switching regression model. The conditional expectation of yields with respect to households that adopted is then given by:

$$
E\left(Y_{A j} \mid D=1\right)=\boldsymbol{X}_{A j} \boldsymbol{\beta}_{A}+\sigma_{A \varepsilon} \rho_{A} \frac{\varphi\left(\boldsymbol{Z}_{\boldsymbol{j}} \gamma\right)}{\Phi\left(\boldsymbol{Z}_{\boldsymbol{j}} \gamma\right)}
$$

The expected output had the household chosen not to adopt zaï pits is given as:

$$
E\left(Y_{N j} \mid D=0\right)=\boldsymbol{X}_{N j} \boldsymbol{\beta}_{N}-\sigma_{N \varepsilon} \rho_{N} \frac{\varphi\left(\boldsymbol{Z}_{\boldsymbol{j}} \boldsymbol{\gamma}\right)}{1-\Phi\left(\boldsymbol{Z}_{\boldsymbol{j}} \gamma\right)}
$$


Expected yields in the hypothetical counterfactual case that the non-adopted farm household adopted are given by:

$$
E\left(Y_{A j} \mid D=0\right)=\boldsymbol{X}_{A j} \boldsymbol{\beta}_{A}-\sigma_{A \varepsilon} \rho_{A} \frac{\varphi\left(\boldsymbol{Z}_{\boldsymbol{j}} \boldsymbol{\gamma}\right)}{1-\Phi\left(\boldsymbol{Z}_{\boldsymbol{j}} \boldsymbol{\gamma}\right)}
$$

while expected yields in the hypothetical case that the adopted farm household did not adopt are given by:

$$
E\left(Y_{N j} \mid D=1\right)=\boldsymbol{X}_{N j} \boldsymbol{\beta}_{N}+\sigma_{N \varepsilon} \rho_{N} \frac{\varphi\left(\boldsymbol{Z}_{\boldsymbol{j}} \gamma\right)}{\Phi\left(\boldsymbol{Z}_{\boldsymbol{j}} \gamma\right)}
$$

The change in the outcome due to adoption can then be specified as the difference between adoption and non-adoption. Thus, the expected outcomes from Eqs. 3a) and 3d) are used to obtain unbiased estimates of the effects of adoption. These estimates represent the average treatment effect on the treated (TT) (Lokshin and Sajaia 2004):

$$
T T=E\left[Y_{A j} \mid D=1\right]-E\left[Y_{N j} \mid D=1\right]=\boldsymbol{X}_{\boldsymbol{A} j}\left(\boldsymbol{\beta}_{A}-\boldsymbol{\beta}_{N}\right)+\left(\sigma_{A \varepsilon} \rho_{A}-\sigma_{N \varepsilon} \rho_{N}\right) \frac{\varphi\left(\boldsymbol{Z}_{\boldsymbol{j}} \boldsymbol{\gamma}\right)}{\Phi\left(\boldsymbol{Z}_{\boldsymbol{j}} \boldsymbol{\gamma}\right)}
$$

Similarly, we can calculate the effect of treatment on the untreated (TU) for the farm households that did not adopt zaï pits as:

$$
U T=E\left[Y_{A j} \mid D=0\right]-E\left[Y_{N j} \mid D=0\right]=\boldsymbol{X}_{N j}\left(\boldsymbol{\beta}_{A}-\boldsymbol{\beta}_{N}\right)+\left(\sigma_{A \varepsilon} \rho_{A}-\sigma_{N \varepsilon} \rho_{N}\right) \frac{\varphi\left(\boldsymbol{Z}_{\boldsymbol{j}} \gamma\right)}{1-\Phi\left(\boldsymbol{Z}_{\boldsymbol{j}} \gamma\right)}
$$

We can also use the expected outcomes to calculate heterogeneity effects. For example, farm households that adopted may have produced more compared to farm households that did not adopt irrespective of the fact that they decided to adopt but because of unobservable characteristics (Di Falco et al. 2011).

$$
B H_{A}=E\left[Y_{A j} \mid D=1\right]-E\left[Y_{A j} \mid D=0\right]=\boldsymbol{\beta}_{A}\left(\boldsymbol{X}_{A j}-\boldsymbol{X}_{N_{j}}\right)+\sigma_{A \varepsilon} \rho_{A}\left(\frac{\varphi\left(\boldsymbol{Z}_{\boldsymbol{j}} \gamma\right)}{\Phi\left(\boldsymbol{Z}_{\boldsymbol{j}} \gamma\right)}-\frac{\varphi\left(\boldsymbol{Z}_{\boldsymbol{j}} \gamma\right)}{1-\Phi\left(\boldsymbol{Z}_{\boldsymbol{j}} \gamma\right)}\right)
$$

Similarly, for the group of households that decided not to adopt, "the effect base heterogeneity" is formulated as:

$$
B H_{N}=E\left[Y_{N j} \mid D=1\right]-E\left[Y_{N j} \mid D=0\right]=\boldsymbol{\beta}_{N}\left(\boldsymbol{X}_{A j}-\boldsymbol{X}_{N j}\right)+\sigma_{N \varepsilon} \rho_{N}\left(\frac{\varphi\left(\boldsymbol{Z}_{\boldsymbol{j}} \gamma\right)}{\Phi\left(\boldsymbol{Z}_{\boldsymbol{j}} \gamma\right)}-\frac{\varphi\left(\boldsymbol{Z}_{\boldsymbol{j}} \gamma\right)}{1-\Phi\left(\boldsymbol{Z}_{\boldsymbol{j}} \gamma\right)}\right)
$$

We use full-information maximum likelihood to simultaneously fit the binary and continuous part of our model to yield consistent standard errors (Lokshin and Sajaia 2004). 


\subsection{Econometric issues}

Although the variables in the vectors $\boldsymbol{X}$ in Eq. (2) and $\boldsymbol{Z}$ in Eq. (1) may overlap, it is important to note that accurate identification requires that at least one variable in $\boldsymbol{Z}$ does not appear in $\boldsymbol{X}$. For the model to be identified, we use as exclusion restrictions not only those automatically generated by the nonlinearity of the selection model of adoption but also other variables that directly affect the selection variable but not the outcome variable. Our selection instruments are a binary variable that takes the value of 1 if the household perceives increased frequency of drought over the 5 years preceding the survey and two village-level variables that capture dedication to agriculture and lagged availability of financial resources. The former measures the distance from the center of the village to the nearest minibus stop while the latter is a binary variable that takes the value of 1 when more than $50 \%$ of households participated in the exode - or seasonal migration - 10 years ago. We establish the admissibility of these instruments by performing a simple falsification test; if a variable is a valid selection instrument, it will affect the adoption decision but it will not affect the quantity produced among farm households that did not adopt. The results from the falsification test (not reported) reveal that drought sensitivity, remoteness, and past labor availability can be considered jointly statistically significant drivers of the decision to adapt to climate change. ${ }^{2}$

An issue that needs to be addressed in estimating both the adoption and outcome specification is the potential endogeneity problem that may arise with the empowerment variable. Empowerment is likely to be endogenous to the production process due to simultaneous effects. Though it may be intuitively appealing to believe that more empowered individuals are more productive, the direction of causality between empowerment and productivity is difficult to establish. Increased empowerment could lead to increased productivity but it is equally possible that increased productivity leads to higher incomes, thereby improving an individual's status of empowerment. Both formal schooling of the highest educated adult and Koranic schooling of adults could also be endogenous with adaptation and agricultural output due to simultaneous effects but this source of bias is likely to be much smaller as educational attainment of an adult has most likely taken place in the past. To account for this potential source of bias, we employ the Rivers and Vuong approach (1988), since one of our dependent variables is dichotomous. The estimation is carried out by first specifying the potential endogenous variable as a function of all other explanatory variables given in the adoption equation, in addition to a set of instruments in the first stage regressions. That is, the specification used is:

$$
\boldsymbol{T}_{i}=\gamma \boldsymbol{Z}_{i j}+\psi \boldsymbol{V}_{i j}+\zeta_{i j}
$$

where $\boldsymbol{T}_{i}$ is a vector of the potential endogenous variables (empowerment), $\boldsymbol{Z}_{\boldsymbol{i} \boldsymbol{j}}$ is as described previously, and $\boldsymbol{V}_{i j}$ is a vector of instruments that is correlated with the given endogenous variable but uncorrelated with the error terms in Eq. (1) and is therefore excluded in estimating this equation. Rather than using the predicted values from the first-stage equation as in a

\footnotetext{
${ }^{2}$ A potential endogeneity problem may arise with the drought-sensitivity variable due to omitted variable bias, e.g., more conscientious households that are more drought sensitive and more likely to have dug zaï pits. However, we do not dispose of suitable instruments to control for this potential bias and we will refrain from any causal inference as to the relation between drought sensitivity and adaptation.
} 
habitual two-stage estimation approach, the approach involves specifying the adoption equation in Eq. (3) as:

$$
D_{i j}^{*}=\beta \boldsymbol{Z}_{i j}+\varphi \boldsymbol{T}_{i}+\boldsymbol{R}_{i j}+v_{i j}
$$

where $\boldsymbol{R}_{i j}$ is a vector of the residual terms from the first-stage regressions of the endogenous variables. The probit estimates of the potential endogenous variables in $\boldsymbol{Z}$ are then consistent (Wooldridge 2002). To ensure identification in the estimation of the adoption specification, some of the variables included in the first stage estimation Eq. (8) are excluded from the selection Eq. (9). Instruments are a variable that describes the difference between the primary male and female in the capacity to be interviewed alone as assessed by the household. A second instrument is a binary variable that takes the value of 1 if the household had indicated to have had access to generic information transmitted via the radio. These variables are expected to be suitable instruments because they are correlated with empowerment but do not independently explain the decision to employ zaï pits or farm output.

Levels of variable inputs (seed, labor, and fertilizer) could also be simultaneously determined with current output because a disturbance in the production equation for example a late start of the rainy season could affect output but also levels of input. This source of bias could render single-equation estimates inconsistent. Instrumental variables - often prices of the various inputs - could be used to address this source of bias. However, as we did not record price information and other instruments are not available, it would be challenging to address this potential source of bias. Instead, we postulate that variable inputs are determined for the current period by household maximization with respect to anticipated output. Because any shifts in the production relation affect actual but not anticipated output, when these shifts occur, the level of input is unaffected (Hoch 1958).

\section{Estimation results}

The results of the estimation of the latent variable model specified in Eq. (9) are given in the third right hand side column of Table 3 and suggest that our three selection variables: increased drought perception, distance to the minibus stop, and high participation in seasonal migration at the village level explain the implementation of zaï pits. If the household perceives that the drought frequency has increased over the 5 years preceding the survey, it is more likely to have put in place zaï pits. This is important as it confirms that perceptions of climatic impacts are a driver of adaptation. The larger is the distance to the minibus stop from the center of the village, the lower the probability of engagement in activities outside own-farm agriculture and the greater is therefore the dedication to agriculture increasing the probability that a household has dug zaï pits. Similarly, the higher the village-level participation in seasonal migration 10 years before the survey took place, the larger the influx of resources in the village through remittances and the more likely it is that households invested in zaï pits.

Our human capital variables - formal and koranic school education, experience, and predicted empowerment - are also positively associated with adaptation (see also Maddison 2007). The variable representing the level of formal education of the highest educated adult household member is positive and significantly different from zero, suggesting that more educated farmers are more likely to construct zaï pits on their land, a finding that is consistent with the notion that 
education is important in helping farmers in their decisions on adopting new innovations and technologies (Huffman 2001; Abdulai and Huffman 2014). The more empowered the household is, the more likely it is to have adapted to climate change by putting in place zaï pits. This means that in addition to the commonly used dimensions of human capital-skills and experience - an expansion in the ability to make strategic life choices will also affect adaptation behavior. In terms of assets, the value of productive equipment is also positive and significant pointing to the importance of resources in determining the capacity to adapt.

We now turn to the productive implications of adoption. The simplest approach to investigate the effect of adoption on production consists of estimating a production function that includes a binary variable, which takes the value of 1 if the farm household implemented zaï pits and 0 otherwise. Estimation results in the first right- and second right-hand side columns of Table 3 show that there are significant and positive returns to zaï pits. Yields also respond positively and significantly to the seeding rate and to labor but to the latter at a decreasing rate. Both literacy of the household head and average empowerment are positively and significantly correlated with cereal yields. This approach, however, assumes that adoption of zaï pits is exogenously determined while it is potentially an endogenous variable. The estimates presented in the last two columns of Table 3 account for the endogenous switching in the cereal production function. Both the estimated coefficients of the correlation terms $\rho_{j}$ are not significantly different from zero (Table 3, bottom row) indicating that the hypothesis of absence of sample selectivity bias may not be rejected. However, there are some differences in the production function of farm households that adapted to climate change by employing zaï pits and those that did not. Households that did not adopt, experience decreasing returns to the seeding rate. It also needs to be noted that returns to empowerment are positive and significant only for households that did not adopt. These differences in the coefficients of the production function between farm households that adopted and those that did not illustrate the presence of heterogeneity in the sample.

Table 4 presents the expected quantity produced per hectare under actual and counterfactual conditions. Cells (a and b) represent the expected quantity produced observed in the sample. The expected yield of farm households that adopted is about $385 \mathrm{~kg}$ per hectare while it is about $325 \mathrm{~kg}$ per hectare for the group of farm households that did not adopt zaï pits. This simple comparison, however, can be misleading and drive the researcher to conclude that on average farm households that adopted produced about $60 \mathrm{~kg}$ per hectare (or 18\%) more than households that did not. The last column of Table 4 presents the treatment effects of zaï pit adoption on cereal productivity. In the counterfactual case (c), farm households who adopted would have produced almost $47 \mathrm{~kg}$ per hectare less (about 14\%) less if they had not adopted. In the counterfactual case (d) that farm households that did not adopt adopted, they would have produced about $110 \mathrm{~kg}$ (or about 34\%) more. These results imply that adaptation to climate change by putting in place zaï pits significantly increases cereal productivity for households in the Tahoua region of Niger. However, the transitional heterogeneity effect is negative and significant, that is, the effect is significantly smaller for the farm households that did adopt relative to those that did not. The last row of Table 4, which adjusts for the potential heterogeneity in the sample, shows that farm households who adopted would have produced significantly more than farm households that did not adopt in the counterfactual case (c).

To reiterate, four important findings emerge from our analysis. First, the perception of climatic change is a driver of adaptation. This means that agricultural adaptation in the face of climate change can be expected to occur autonomously to some extent and that the role for government could center on lowering barriers to adaptation (see also Maddison 2007). Second, 


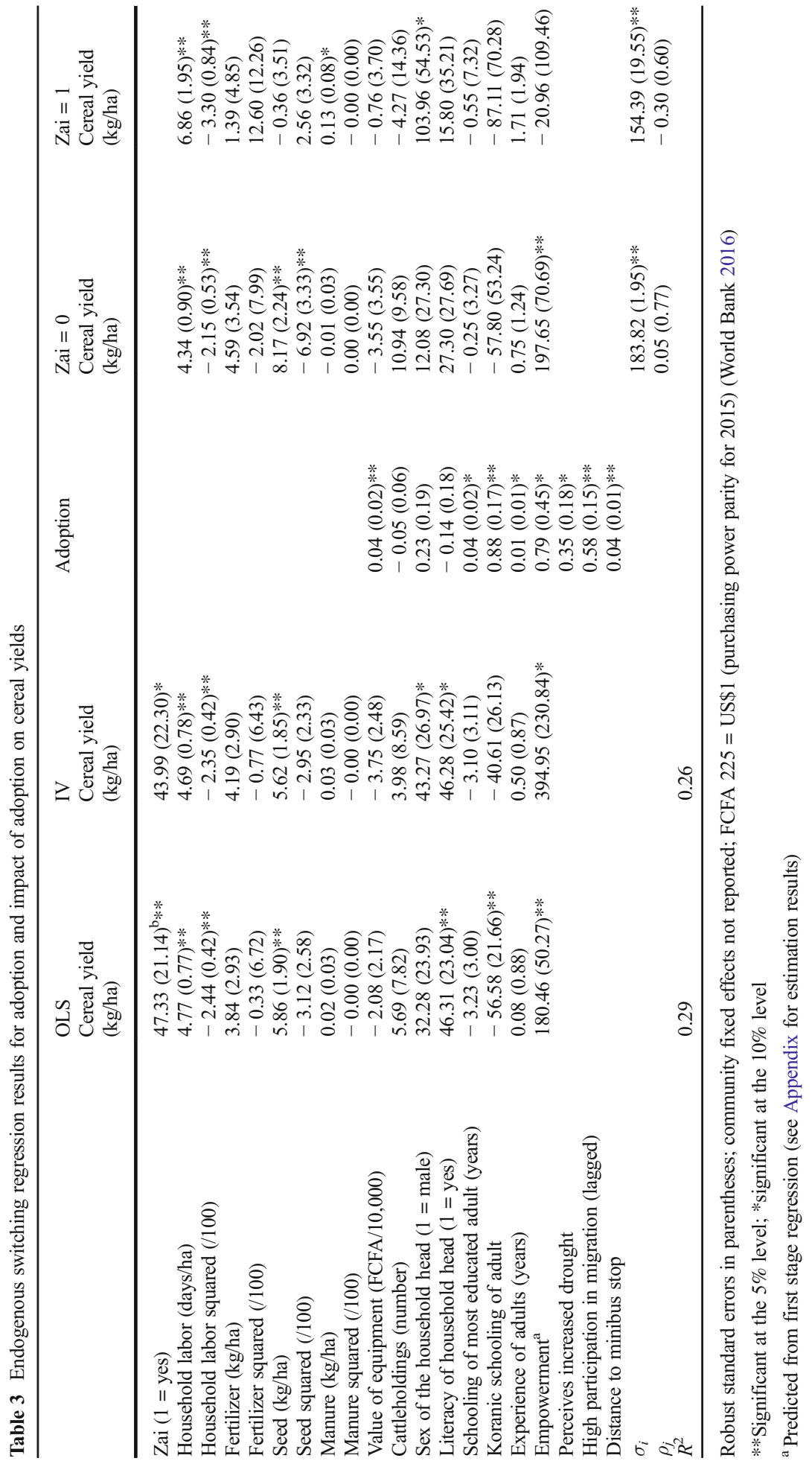


Table 4 Impact of zaï pits on cereal yields

Decision stage

\begin{tabular}{llll}
\cline { 2 - 4 } Impact & To adopt & Not to adopt & Treatment effects \\
\hline Farm households that adopted & (a) $385.11(14.42)$ & (c) $338.44(10.19)$ & $46.67(11.01)^{* * * *}$ \\
Farm households that did not adopt & (d) $435.14(8.29)$ & (b) $325.26(5.73)$ & $109.88(6.07)^{* * *}$ \\
Heterogeneity effects & $-50.03(6.08)^{* * *}$ & $13.18(2.72)^{* * *}$ & $-63.21(6.70)^{* * *}$ \\
\hline
\end{tabular}

Standard errors in parentheses

*** Significance at the $1 \%$ level

empowerment positively affects adaptation behavior. This means that an expansion in the ability to make strategic life choices will contribute to adaptation to climate change. Because the leadership domain - comprising of group membership and ease of speaking in public in front of a mixed audience - is an important contributor to inadequacy in empowerment, relatively soft interventions such as encouraging households to become a member of an existing group or organizing leadership training could contribute to climate change adaptation and productivity. Third, adaptation to climate change by putting in place zaï pits significantly increases cereal productivity and thereby household incomes and welfare. These findings are consistent with the view that adoption of new agricultural technologies can improve farm productivity and household incomes (Abdulai and Huffman 2014). Fourth, farm households belonging to the group of adapters have some characteristics (e.g., unobserved skills) that would make them more food secure even without the implementation of the adaptation strategies. This finding highlights, in line with findings of Di Falco et al. (2011) for rural Ethiopia, that there are some important sources of heterogeneity that make adopters "better producers" compared to those that did not irrespective of the issue of climate change. Therefore, adoption of zaï pits seem to be particularly important for the most vulnerable farm households, those who are less able to produce food, by helping them to close the productivity gap with less vulnerable farm households (Di Falco et al. 2011).

\section{Conclusion}

The objectives of this study were to analyze the driving forces behind the decision of farm households in the Tahoua region of Niger to adapt to climate change by implementing zaï pits and to investigate the productive implications of this decision. We have contributed to the existing literature by empirically establishing a relationship between drought perception and adaptation and by assessing the role that empowerment plays in adaptation and productivity. We have used recent household and individual level WEAI data to estimate a simultaneous equation model with endogenous switching to account for household self-selection into adoption. We find that households that perceived increased drought were more likely to have employed zaï pits but that important human capital-related obstacles to adaptation exist. We find, for example, that inadequacy in empowerment hampers zaï pit adoption. Our results reveal that productivity is higher in households that had implemented zaï pits. Heterogeneity effects imply that yield gains would be particularly large for non-adopting households if they were to adopt.

Our findings have considerable implications for policy measures aimed at enhancing and facilitating climate change adaption in rural Niger and elsewhere. First, they suggest that the 
perception of an increase in drought frequency can prompt households into adaptative action. Climate change adaptation can thus take place autonomously and rather than planning climate change adaptation strategies, programs and interventions could more usefully focus on alleviating barriers to adaptation. Second, our findings speak to the importance of empowerment as a development goal, both for its intrinsic value, and as demonstrated here for its instrumental value in promoting adaptation and its productivity effects, particularly for vulnerable households. It is therefore important for policy makers aiming to enhance agricultural productivity of those households to consider empowerment-augmenting programs and interventions. For households in rural Niger, softer interventions such as leadership training or encouraging membership of groups such as producer groups or rotating savings schemes are expected to be particularly effective.

\section{Appendix}

Table 5 First-stage regression for empowerment

\begin{tabular}{|c|c|}
\hline & Empowerment \\
\hline Household labor (days/ha) & $0.001(0.001)$ \\
\hline Household labor squared (/100) & $-0.001(0.001)$ \\
\hline Fertilizer $(\mathrm{kg} / \mathrm{ha})$ & $-0.003(0.002)$ \\
\hline Fertilizer squared $(/ 100)$ & $0.005(0.003)$ \\
\hline Seed $(\mathrm{kg} / \mathrm{ha})$ & $0.000(0.001)$ \\
\hline Seed squared $(/ 100)$ & $-0.000(0.002)$ \\
\hline Manure $(\mathrm{kg} / \mathrm{ha})$ & $-0.000(0.000)$ \\
\hline Manure squared (/100) & $0.000(0.000)$ \\
\hline Value of equipment (FCFA/10000) & $0.005(0.002)^{* *}$ \\
\hline Cattleholdings & $0.015(0.006)^{* *}$ \\
\hline Sex of the household head $(1=$ male $)$ & $-0.045(0.019)^{* *}$ \\
\hline Literacy of household head ( 1 = yes) & $-0.055(0.019) * *$ \\
\hline Schooling of most educated adult (years) & $0.005(0.002)^{* *}$ \\
\hline Koranic schooling of adult & $-0.037(0.019) * *$ \\
\hline Difference in capacity to be interviewed alone between primary male and female & $-0.096(0.025)^{* *}$ \\
\hline Access to generic information via the radio & $0.069(0.017)^{* *}$ \\
\hline$R^{2}$ & 0.21 \\
\hline Adjusted $R^{2}$ & 0.18 \\
\hline Kleibergen-Paap Wald rk F statistic & 13.90 \\
\hline \multicolumn{2}{|l|}{ Stock-Yogo critical values } \\
\hline $10 \%$ maximal IV relative bias & 19.93 \\
\hline $15 \%$ maximal IV relative bias & 11.59 \\
\hline $20 \%$ maximal IV relative bias & 8.75 \\
\hline Hansen $\mathrm{J}$ statistic ( $p$ value) & $0.50(0.48)$ \\
\hline Durbin (score) $\chi^{2}(1)$ ( $p$ value) & $1.03(0.31)$ \\
\hline Number of observations & 488 \\
\hline
\end{tabular}

Open Access This article is distributed under the terms of the Creative Commons Attribution 4.0 International License (http:/creativecommons.org/licenses/by/4.0/), which permits unrestricted use, distribution, and reproduction in any medium, provided you give appropriate credit to the original author(s) and the source, provide a link to the Creative Commons license, and indicate if changes were made. 


\section{References}

Abdulai A, Huffman W (2014) The adoption and impact of soil and water conservation technology: an endogenous switching regression application. Land Econ 90(1):26-43

Adger WN, Arnell NW, Tompkins EL (2005) Successful adaptation to climate change across scales. Glob Environ Chang 15(2):77-86

Adger WN, Dessai S, Goulden M, Hulme M, Lorenzonirene, Nelson DR, Naess LO, Wolf J, Wreford A (2009) Are there social limits to adaptation to climate change? Clim Chang 93(3-4):335-354

Alkire S, Meinzen-Dick R, Peterman A, Quisumbing AR, Seymour G, Vaz A (2013) The women's empowerment in agriculture index. World Dev 52:71-91

Burnham M, Ma Z (2016) Linking smallholder farmer climate change adaptation decisions to development. Climate Dev 8(4):289-311

Di Falco S, Veronesi M, Yesuf M (2011) Does adaptation to climate change provide food security? A microperspective from Ethiopia. Am J Agric Econ 93(3):825-842

Grothmann T, Patt A (2005) Adaptive capacity and human cognition: the process of individual adaptation to climate change. Glob Environ Chang 15(3):199-213

Heckman J (1979) Sample selection bias as a specification error. Econometrica 47(1):153-161

Hoch I (1958) Simultaneous equation bias in the context of the Cobb-Douglas production function. Econometrica 26(4):566

Howden SM, Soussana JF, Tubiello FN, Chhetri N, Dunlop M, Meinke H (2007) Adapting agriculture to climate change. Proc Natl Acad Sci 104(50):19691-19696

Huffman WE (2001) Human capital: education and agriculture. In: Gardner BL, Rausser GC (eds) Handbook of Agricultural Economics IB. Elsevier Science, Amsterdam

IFAD. 2010. Niger: managing rainfall with tassa. Available from http://www.ifad.org/english/water/innowat/cases/niger. htm. Accessed 4 Sept 2017

Intergovernmental Panel on Climate Change, 2014. Climate change 2014-impacts, adaptation and vulnerability: regional aspects. Cambridge University Press

Kaboré, D. and Reij, C., 2004. The emergence and spreading of an improved traditional soil and water conservation practice in Burkina Faso(Vol. 114). Washington DC International Food Policy Research Institute

Lamanna C, Ramirez-Villegas J, Van Wijk M Corner-Dolloff C, Girvetz E, Rosenstock TS 2015 Evidence- and risk-based planning for food security under climate change Results of a modeling approach for climate-smart agriculture programming. CCAFS Info Note. CCAFS

Laroche M, Mérette M, Ruggeri GC (1999) On the concept and dimensions of human capital in a knowledgebased economy context. Canadian Public Policy/Analyse de Politiques 25(1):87

Lee L-F (1982) Some approaches to the correction of selectivity bias. Rev Econ Stud 49(3):355-372

Lokshin Ml, Sajaia Z (2004) Maximum likelihood estimation of endogenous switching regression models. Stata J 4(3):282-289

Maddison DJ (2007) The perception of and adaptation to climate change in Africa. World Bank Policy Research Working Paper No. 4308. World Bank, Washington

Nelson GC, Rosegrant MW, Koo J, Robertson R, Sulser T, Zhu T, Ringler C (2009) Climate change: impact on agriculture and costs of adaptation. International Food Policy Research Institute, Washington

Reij C, Tappan G, Smale M (2009) Agroenvironmental transformation in the Sahel. Another kind of green revolution. International Food Policy Research Institute, Washington

Rivers D, Vuong QH (1988) Limited information estimators and exogeneity tests for simultaneous probit models. J Econ 39(3):347-366

Seymour G, Doss CR, Marenya P, Meinzen-Dick R, Passarelli S 2016 Women's empowerment and the adoption of improved maize varieties: evidence from Ethiopia, Kenya, and Tanzania. Selected Paper prepared for presentation at the 2016 Agricultural \& Applied Economics Association Annual Meeting, Boston, MA, July 31-August 2

UNDP (2013) Human development report 2013: the rise of the south: Human progress in a diverse world. UNDP, New York

Wooldridge JM (2002) Introductory econometrics: a modem approach. Thomson South-Western, Mason

World Bank 2013 Agricultural sector risk. Assessment in Niger: moving from crisis response to long-term risk management. Agriculture and Environmental Services (AES) Department and Agriculture, Rural Development, and Irrigation (AFTAI) Unit in the Africa Region Report No. 74322-NE. Washington DC: World Bank

World Bank (2016) Available at data.worldbank.org/indicator/NV.AGR.TOTL.ZS/countries/1W-NE?display= graph. Accessed 3 Nov 2016

Wouterse FS (2017) The returns to empowerment in diversified rural household: evidence from Niger, vol 1611. International Food Policy Research Institute, Washington 